\title{
Students and recorded lectures: survey on current use and demands for higher education
}

\author{
Pierre Gorissen ${ }^{\mathrm{a} *}$, Jan van Bruggen ${ }^{\mathrm{b}}$ and Wim Jochems ${ }^{\mathrm{c}}$ \\ ${ }^{a}$ Educational Development and Research Department, Fontys University of Applied Sciences, \\ Eindhoven, the Netherlands; ${ }^{b}$ Fontys School of Teacher Training, Fontys University of Applied \\ Sciences, Eindhoven, the Netherlands \& CELSTEC, Open University of the Netherlands, \\ Heerlen, the Netherlands; ${ }^{c}$ Eindhoven School of Education, Eindhoven University of Technology, \\ Eindhoven, the Netherlands
}

(Received 14 November 2010; final version received 5 March 2012)

\begin{abstract}
Online recordings of lectures provide students with anytime-anyplace access to lectures. Research shows that students prefer courses accompanied by online recordings and an increasing number of universities provide recorded lectures. This paper presents the results of a study into the use of recorded lectures at two universities in the Netherlands. The goal of the study is to gain a better understanding of the way that this group of students use recorded lectures. This understanding will enable the creation of usage scenarios that need to be supported. Our results show that students use recorded lectures as a replacement for missed lectures and for study tasks, like preparing for an exam. A large proportion of the students report that they watch $75-100 \%$ of a recorded lecture when the view one. The fact that students did not mention the quality of the actual lectures appears not to influence the use of the recorded lectures. Recorded lectures for courses that only use the blackboard are viewed less often. There are also interesting differences in the use of recorded lectures of the different groups of students at the two universities. To increase the credibility and validity of the results, we need a more direct way to measure the use of recorded lectures by students. Methodological triangulation using the log data for the recorded lectures can provide this.
\end{abstract}

Keywords: recorded lectures; web lectures; online lectures; video lectures

\section{Introduction}

The lecture is the most common form of teaching method in institutions of higher education throughout the world (Behr 1988). Its prevalence has been criticised by many (Phillips 2005; Sheely 2006), yet this criticism has not lead to significant changes in the form or frequency of use of lectures. An increasing number of universities choose to support student learning by providing online recordings of lectures (Leoni and Lichti 2009). These recorded lectures provide students with more control over their schedules and learning, allowing them to review lectures at their own pace and at a time and place of their choosing. Thus, recordings offer a more learner-centered approach for lectures (Baecker, Moore, and Zijdemans 2003; Traphagan, Kucsera, and Kishi 2010).

*Corresponding author. Email: P.Gorissen@fontys.nl 


\section{P. Gorissen et al.}

Research by Traphagan (2005, 2006), Veeramani and Bradly (2008) and Gosper et al. (2008) shows that most students express a preference for courses accompanied by online recordings of the lectures. This is not only the case for traditional distance students, but also for on-campus students as well (Woo et al. 2008). Chang (2007) examined teacher and staff perception towards lecture recordings and results show they favour the use of recorded lectures as well. Little is known, however, about the way in which students navigate within the recordings or how they find (the parts of) the recordings they want to watch. Most studies are limited to the overall opinions and perceptions of students and lecturers about usefulness of the recorded lectures.

This article reports on a study into the use of recorded lectures by students at two universities in the Netherlands. The study looks only at full length recorded lectures of live lectures, the most frequently type of recordings created at both universities, consisting of recordings of 40-45 minutes lectures. This study is part of a larger research project into the use of recorded lectures by students that aims to improve the support for recorded lectures by students within different usage scenarios.

In this stage of the larger body of our research, we asked students directly about their usage of recorded lectures. In the next stage, we will explore means to measure their use of the recorded lectures and the way in which they navigate through the recorded lectures. The goal of this first stage of the research is to get a better understanding of the way this group of students use recorded lectures. This will enable us to create student usage scenarios that need to be supported. In this article, we want to address the following questions: Where and when do students watch the recorded lectures? With what purpose do they watch? If they did not watch the recorded lectures, for what reason did they not watch? Is there a relationship between the use of recorded lectures and the level of ambition of students, the ease of use of the recorded lectures, or the use of other resources available to the student?

This study goes beyond the existing body of research by applying a sampling method that is different from other studies. We specifically selected students with recent exposure to recorded lectures and surveyed them about their use within a single specific course. Both users of the recorded lectures and non-users were included in the study. The subjects were all on-campus students who were able to attend the face-to-face lectures. And although the results are reported anonymously, the survey data allows us to compare the results of this first stage with the results of the second stage of the research. This means we will be able to compare the reported use of the recorded lectures with the actual use of the recorded lectures.

\section{Lecture capturing}

There are a number of ways in which video can enhance lectures. Weblectures are video recordings that have been specifically made for use as educational resources (Day 2008). They consist of a studio recording containing a combination of video and audio with a synchronized view of the lecturer's computer screen while displaying a presentation. Weblectures usually do not exceed 20 minutes. A variation on the weblecture is the screencast (Udell 2004). There the focus is on what happens on the screen, for example, to explain the usage of a computer application. Screencasts can contain video of the presenter, but usually only contain the audio and a recording of the screen. Because weblectures and screencasts are recorded in advance and in a controllable setting, their quality level can be reasonably high. The story they tell can 
be scripted in advance, re-takes of the recording are possible and they can be made available to students in advance of the actual lecture.

Lecture capturing involves the capturing of a live lecture situation. The lecture dictates the length, contents and structure. Early lecture-capturing systems often did not include video of the lecturer. One reason for this was that previously the speed of internet connections available to students required high video compression, low frame rates and small frame size (Fardon 2003). One way used to solve bandwidth problems was to create downloadable podcasts that contained audio only or audio and video (Belanger 2005; Campbell 2005; Chan, Lee, and Mcloughlin 2006).

In the conversational framework, Laurillard (2002) uses the concept of "affordances" (Gibson 1979) of multimedia to match them with learning activities. Modern lecture capture systems have a number of additional affordances when compared to more traditional media like a DVD, videocassette or even television broadcasts. Students have direct, on demand or live, access to the recorded lectures. They can play, pause and replay parts of the recorded lecture as often as they like. They can also annotate the recorded lectures, either directly in the interface provided by the lecture capture system, or by saving links (favourites) to parts of the recorded lecture.

Most universities in the Netherlands use commercially available systems to capture lectures; some have home-grown solutions. Both universities that participated in this research study use a lecture capturing system (LCS) called Mediasite by SonicFoundry (Sonicfoundry 2010). All recordings are available online only; currently, no downloadable versions of the recordings are provided by either of the two universities.

The LCS used in this study consists of a combination of hardware and software. It captures a number of different media at once. An external video camera captures the video of the lecturer. The audio, captured through the lecturer's wireless microphone, is recorded and relayed to the system. Finally, the VGA signal, normally sent directly to the projector, is rerouted through the lecture-capturing system, where it is recorded along with the audio and video of the presenter. The LCS automatically adjusts the recording and synchronisation of the recorded audio, the video and the VGA signal. When the recording is complete, it is automatically uploaded to a server and made available for students. Students' notes are not recorded by the system. Students either use paper and pen to create notes or use their laptops to type notes during the lecture.

The user interface consists of a three-window display (Figure 1): one featuring the video of the instructor (1), one showing the captured VGA signal as displayed on the projector (2) and one showing general information about the recording (3). Students can move the video play to a specific time in the lecture and play the presentation at faster or slower speeds, as needed. They also can switch to a slide-based view (not shown in the figure). This view shows captures of the slides, generated by the capturing system, that allow direct navigation to certain parts of the lecture.

\section{The study}

\section{Participants}

Participants were students at either the School of Nursing at Fontys University of Applied Sciences in the Netherlands, or from various faculties of the Eindhoven 


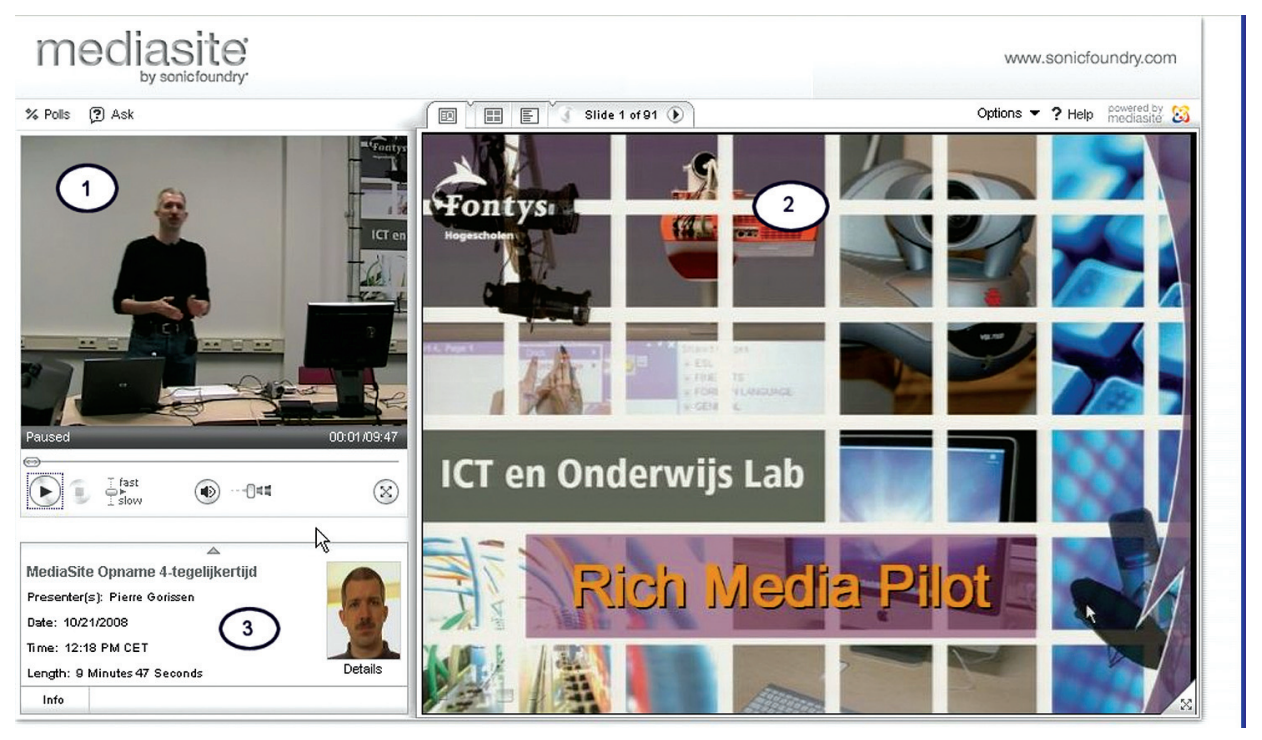

Figure 1. Mediasite LCS user interface of recorded lecture.

University of Technology (TU/e). Student selection was based on their recent participation in a course that used recorded lectures (second half of 2009). The courses all had a set of lectures that were recorded on a regular basis (weekly or more often). Students were questioned about one specific course in order to keep the overlap between subgroups as small as possible. The students were provided with online recordings of lectures that they could also attend in person. This meant they had the choice between either attending the lecture, viewing it online, or both.

For the Fontys students, these criteria limited the number of available students to 203 students participating in a single course. For TU/e, students were selected from three courses with a large number of views and three courses with a small number of views. The six courses had minimal overlap: Only eight students had registered for more than one of the six courses selected for this study. This selection method led to a total group of 919 students for all six TU/e courses. Most Fontys students in the participant group were female $(81.3 \%)$ while most TU/e students in the participant group were male $(84.7 \%)$.

Table 1 shows the seven courses that were included in the survey. The courses were part of six different departments; both the C05 Vector calculus and the C06 Calculus course were conducted by the Applied Mathematics department. The Fontys course was aimed at first year students of the School of Nursing, while the TU/e courses were aimed at both third, second and first year students from different programs of TU/e. $83.5 \%$ of the Fontys respondents and $20.0 \%$ of the TU/e respondents are female, resulting in a slight overrepresentation of females in the responses.

Most of the recordings are traditional university-style lectures, with the teacher standing in front of the class lecturing. Exceptions to this were lectures where assignments and the test were discussed.

All recordings are between 35-45 minutes long. In all of the recordings, video of the lecturer is recorded and displayed. Five of the courses used PowerPoint or other computer-based applications recorded alongside the video of the lecturer, as shown 
Research in Learning Technology

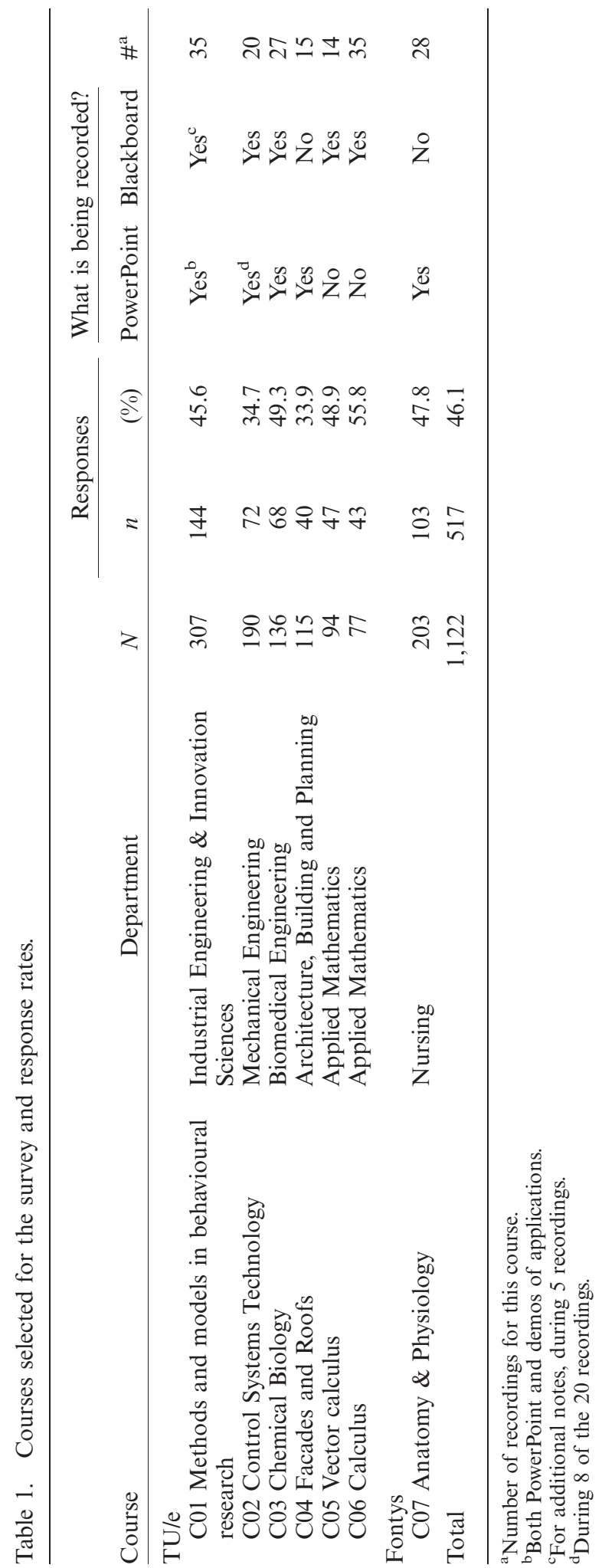




\section{P. Gorissen et al.}

in Figure 1. Two of the courses only used the blackboard during the lectures. In these cases, the same camera was used to record both the lecturer and the blackboard. The interface, as shown in Figure 1, displays a static image as part of window (2) that otherwise would display the captured VGA signal.

\section{Materials and procedures}

During this stage of the research, the study consisted of two parts: an online survey and a number of semi-structured interviews. The online survey contained 17 questions using both multiple choice and Likert scale questions. Some of the questions are based on questions used in other surveys on the use of recorded lectures (Hall 2009; Kishi and Traphagan 2007; Traphagan 2006; Veeramani and Bradly 2008; Wieling 2008; Williams and Fardon 2007; Zupancic 2006). Students were able to complete the survey in about $10-15$ minutes.

The first part of the survey asked students for their interest in the topic of the course, the perceived importance of the course for their course of study and the grade they wished to achieve for the course. In the second part of the survey, students rated the effectiveness of a number of available activities (e.g., attending face-to-face lectures) and supporting resources (e.g., slides, lecture notes, etc.) in helping them to succeed in the course. It also asked about any previous experience with lecture recordings, and whether they had used the recorded lectures for the course in question. In part three of the survey, those students who had used the lecture recordings were surveyed in more detail about their experiences during that use. Those questions were not displayed to students that indicated they had not used the recorded lectures. The final part of the survey contained questions for all students, seeking out reasons they did not watch one or more of the recorded lectures (if applicable). We reviewed the survey and tested it online with a number of peers and experts.

We approached the students using a personalized e-mail that contained the link to the web-based survey. In the e-mail and the survey itself, the students were reminded to complete the survey based on their experiences and use for the one specific course mentioned. The survey was open online for 2 weeks. An e-mail reminder was sent after 1 week and again on the final day of the survey to those students who had not completed the survey.

All questions in the survey and informational e-mails were provided in both Dutch and English because some of the international students at TU/e prefer English over Dutch. Students could switch between the Dutch and English versions while filling out the survey. As part of the survey, we invited students for follow-up questions. A total of 120 students accepted the invitation initially. Of those students, 14 were interviewed using a semi-structured interview lasting 30 minutes. During the interviews, students were asked to elaborate on their use of the recordings during the course. The interviews were recorded and transcribed.

\section{Results}

The total response rate for the survey was $517(46.1 \%, N=1122)$. Nineteen partially completed surveys were included in the results. The survey contained a number of questions that were displayed only when the student had indicated that he or she had watched the recordings. Because of this, not all students completed all the questions, 
and the number of responses may differ between questions. Where relevant in this article, the actual number of responses $(n)$ is indicated in the remainder of the results section.

Most students participating in the survey had a positive attitude towards the course in question. Of all respondents, $74.2 \%$ felt that the topic of the course was important, and $83.9 \%$ agreed that the course was an important part of their study. Students were asked about their level of ambition for this course. TU/e students, on average, aim for a 7.35 on a 10 -point scale $(\mathrm{SE}=0.97)$ on the exam. The mean for Fontys students is 4.18 on a 5 -point scale $(\mathrm{SE}=0.789)$. Students are motivated for the course and see it as an important part of their study.

Table 2 shows the number of times respondents indicated they used recorded lectures for the course. When compared to the TU/e, there were more heavy users amongst the Fontys respondents. However, these respondents, who might have a more positive attitude towards the recordings, were not overrepresented in the total responses for the survey.

A Chi-square test for interdependence indicated a significant association between the course and the number of times respondents used the recorded lectures, $\chi^{2}(18$, $n=513)=183.280, p<0.0005$, Cramer's $\mathrm{V}=0.345$. There also is a significant association between what is recorded (PowerPoint, blackboard, or both PowerPoint and the blackboard) and the number of times respondents used the recorded lectures, $\chi^{2}(6, n=513)=86.937, p<0.0005$, Cramer's $\mathrm{V}=0.291$. Of all students from the courses where only the blackboard was recorded, $48.9 \%$ never used the recorded lectures and $36.7 \%$ used the recorded lectures less than five times. A Chi-square test for interdependence showed no statistically significant difference in the number of times that students used the recorded lectures and their reported interest in the topic of the course, $\chi^{2}(12, n=513)=17.099, p=0.146$, or the indicated importance of the course for their course of study, $\chi^{2}(9, n=513)=15.593, p=0.174$. There also was no statistically significant difference in the grade that students wished to achieve and the number of times that students used the recorded lectures, $\chi^{2}(9, n=513)=4.525$, $p=0.874$.

Table 3 shows that there was a significant difference between TU/e and Fontys students with regard to prior experience with recorded lectures. Of the students who had used recorded lectures for their course five times or more, 65.3\% had prior experience with recorded lectures. Of the students who did not use recorded lectures, $53.4 \%$ had no prior experience with recorded lectures. Spearman's Rank Order correlation analysis shows a weak positive relationship for the TU/e students between prior experience with recorded lectures and the number of times that students used the recorded lectures $\left(r_{\mathrm{s}}=0.266, n=410, p<0.0005\right)$. Spearman's Rank Order

Table 2. Number of times respondents used recorded lectures for the course.

\begin{tabular}{|c|c|c|c|c|c|c|}
\hline & \multicolumn{2}{|c|}{ Fontys } & \multicolumn{2}{|c|}{ TU/e } & \multicolumn{2}{|c|}{ Total } \\
\hline & $n$ & $(\%)$ & $n$ & $(\%)$ & $n$ & $(\%)$ \\
\hline Never & 7 & 6.8 & 111 & 27.1 & 118 & 23.0 \\
\hline$<5$ times & 13 & 12.6 & 97 & 23.7 & 110 & 21.4 \\
\hline 5-10 times & 35 & 34.0 & 111 & 27.1 & 146 & 28.5 \\
\hline$>10$ times & 48 & 46.6 & 91 & 22.2 & 139 & 27.1 \\
\hline
\end{tabular}


Table 3. Ever used recorded lectures before.

\begin{tabular}{lcc}
\hline & Fontys $(n=103)(\%)$ & TU/e $(n=410)(\%)$ \\
\hline Yes & 25.2 & 71.7 \\
No & 74.8 & 28.3 \\
\hline
\end{tabular}

correlation analysis shows no statically relevant relationship for the Fontys students $\left(r_{\mathrm{s}}=-0.067, n=103, p=0.504\right)$.

\section{Where and when do students watch the recorded lectures?}

Almost all students (Fontys: 99.0\%, $n=96$; TU/e: 90.3\%, $n=299$ ) access the recorded lectures from home. Some students used the "other" option to indicate that they access the recordings from both home and the university. $44.9 \%$ indicated that there had been no technical difficulties at all while viewing the recorded lectures. Table 5 gives an overview of the reported technical difficulties.

Bandwidth should no longer be a problem in the Netherlands where $89 \%$ of the households have internet access at home and 79\% have broadband connections (TNS Opinion \& Social 2010). Yet, about $90 \%$ of all reports of technical difficulties in Table 4 were from students that viewed the recorded lectures from home, suggesting that either bandwidth problems or problems with the computer configuration at home still might be a bigger issue than on the university campus.

Only $36.4 \%$ (Fontys: $36.9 \%, n=103$; TU/e: $36.2 \%, n=414$ ) of students surveyed watch the recordings on the same day or during the same week as the lecture. A large number of students indicate that they use the lecture recordings while preparing for exams at the end of the course. This is supported by their responses on questions related to the purpose for watching recorded lectures.

One student, who participated in the Methods and models in behavioural research course, commented during the interview:

For an exam that I really wanted to pass, I started watching the recorded lectures again, a couple of days before the exam. I would watch for 20 minutes, take a short break and then watch for another 20 minutes. That way I could watch about 10 recordings on a single day. (IVR4)

\section{With what purpose do students watch?}

We asked students how important different purposes of recorded lectures were to them. Table 5 shows that making up for a missed lecture and preparing for the exam

Table 4. Reported technical difficulties.

\begin{tabular}{lcc}
\hline & $\begin{array}{c}\text { Fontys } \\
(n=103)(\%)\end{array}$ & $\begin{array}{c}\text { TU/e } \\
(n=166)(\%)\end{array}$ \\
\hline There were no technical difficulties & 61.1 & 40.1 \\
Bad quality/intelligibility of the audio & 10.7 & 9.7 \\
Bad video quality & 2.9 & 12.6 \\
Slides and video do not play synchronous & 3.9 & 10.1 \\
Loading the presentation takes a long time & 5.8 & 3.1 \\
The playback of the presentation stops to buffer/load & 5.8 & 7.5 \\
Presentation doesn't play at all & 3.9 & 1.9 \\
\hline
\end{tabular}


Table 5. Indicated importance of lecture recording for different purposes.

\begin{tabular}{lcc}
\hline & \multicolumn{2}{c}{ Somewhat or very important } \\
\cline { 2 - 3 } & Fontys $(n=90)(\%)$ & TU/e $(n=294)(\%)$ \\
\hline Making up for a missed lecture & 90.0 & 96.9 \\
Preparing for the exam & 96.6 & 84.2 \\
Improving test scores & 88.9 & 80.3 \\
Improving retention of lecture materials & 91.1 & 74.8 \\
Clarifying the material & 89.9 & 70.8 \\
Replacing live attendance & 66.7 & 70.4 \\
Reviewing material after a lecture & 75.6 & 50.7 \\
Assisting with an assignment & 57.8 & 51.7 \\
Reviewing material before a lecture & 70.0 & 36.1 \\
Checking own notes & 71.1 & 34.0 \\
Reinforcing the experiences at the live lecture & 63.3 & 30.3 \\
Managing distractions during lectures & 64.4 & 28.5 \\
Overcoming language barriers & 16.7 & 8.8 \\
\hline
\end{tabular}

score high for both TU/e and Fontys students. The table also shows a number of differences between the TU/e and Fontys students. Fontys students rate the importance of recorded lectures to manage distractions during lectures, to check their own notes, to reinforce the experiences at the live lecture, and to review the material before a lecture about twice as often as "somewhat important" or "very important". One possible explanation for the differences found is that the Fontys students were first-year students, less used to structuring their own learning than the mostly second and third year students in the TU/e group. Differences in individual courses, the way the lecturer presented or the topic of the course could also account for the differences in responses.

The use of the recorded lectures to overcome language barriers, as suggested by previous research (Schok 2007), was not confirmed by this survey.

During the interviews, students said that the recorded lectures enabled them to organize their schedule:

I am an active student, have a number of other activities and obligations. This means I am not always able to attend the live lectures. [...] Lectures are sometimes noisy and the recordings enable me to view them without distraction, even the night before the test. (IVR14)

Reasons for not attending the lectures were other obligations, other lectures even, incorrect planning on my part or overlap in the lectures scheduled by the university. (IVR3)

This course was scheduled on a Monday morning. It was my only course on that day so I only attended the live lecture once and watched the rest online. (IVR2)

\section{How often and how much do students watch recorded lectures?}

Fontys has a higher percentage of students than the TU/e that indicated they had used the recordings more than 10 times (see Table 2). Table 6 shows that they also have more students that report that watch most of the recordings. When asked how much of a recording they watch, $68.5 \%$ of respondents (Fontys: $73.4 \%, n=94$; TU/e: $67.0 \%, n=297$ ) say they typically watch at least three quarters of the recording. 
Table 6. Average percentage of a recording viewed.

\begin{tabular}{lccc}
\hline & Fontys $(n=94)(\%)$ & TU/e $(n=297)(\%)$ & Total $(n=391)(\%)$ \\
\hline $0-10 \%$ & 2.1 & 4.4 & 3.8 \\
$10-25 \%$ & 1.1 & 3.0 & 2.6 \\
$25-50 \%$ & 4.3 & 6.4 & 5.9 \\
$50-75 \%$ & 19.2 & 19.2 \\
$75-100 \%$ & 19.1 & 67.0 & 68.5 \\
\hline
\end{tabular}

During the interviews, students confirmed that they usually view the complete recording:

I watch the whole recordings, I do not skip parts. Though while preparing for the exams

I only watch the parts that I think I need to watch again. (IVR2)

During the three weeks before the exams, I watched more than half of all the recorded lectures [for the course] completely and created additional notes based on that. (IVR6)

If I have not attended the lecture, I watch the recording from start to finish. (IVR7)

I start the recording and watch it once from start to finish. (IVR8)

\section{Reasons not to watch recorded lectures}

Only a small number of students did not watch a recorded lecture because they didn't know that they were available. Table 7 shows the reasons selected by students for not watching one or more of the recordings. The most important reason cited for not watching a recorded lecture is because they already had been to the live lecture.

A number of students $(2.1 \%$ overall) used the "other reasons" option to indicate they watched all the available recordings. During the interview phase, one of the students from the Chemical Biology course stated:

I never watch the recorded lectures if I've already attended the lecture. But I had to retake the exam for the [...] course this year, and instead of going to the lectures, I only reviewed the recorded lectures for that course to prepare for the exam. (IVR3)

\section{Relationship between ease of use and student use}

Only a small number of respondents (Fontys: 6.8\%, $n=103$ and TU/e: $6.3 \%, n=414$ ) chose technical difficulties as a reason for not watching a recorded lecture. A Spearman's Rank Order correlation analysis shows a weak positive relationship

Table 7. Reasons to not watch one or more of the recordings.

\begin{tabular}{lcc}
\hline & Fontys $(n=103)(\%)$ & TU/e $(n=414)(\%)$ \\
\hline Because I did not know that they were available & 3.9 & 7.2 \\
Because I did go to class & 43.7 & 57.0 \\
Because of technical difficulties & 6.8 & 6.3 \\
Because I never felt I missed anything important & 10.7 & 21.7 \\
Because I did not have time for it & 26.2 & 19.3 \\
Because I do not like to watch them & 1.0 & 5.1 \\
Because the quality of the recordings was bad & 0.0 & 6.5 \\
\hline
\end{tabular}


between students that rate the ease of navigation higher and the use of lecture recordings $\left(r_{s}=0.295, n=384, p<0.0005\right)$. Furthermore, a weak positive correlation was found between students that rate the ease of finding specific parts of the recording they want to watch higher and the use of lecture recordings $\left(r_{s}=0.270\right.$, $n=384, p<0.0005)$. Students like both the possibility to pause/stop the video while taking notes and to replay the recorded lecture at high speed when reviewing the recorded lecture:

The advantage of the recording is that I can pause the video. That comes in handy for example when I want to copy a complex chemical structure formula while he is explaining that formula. (IVR1)

I'm glad I can stop and rewind the video, take notes, and if needed, rewind again. (IVR8)

I often watch a recording at about 1.4 or 1.6 times normal speed to speed things up. (IVR14)

\section{Relationship between use of recorded lectures and other resources available to the student}

The survey asked students to rate a number of other resources on their effectiveness in helping them to succeed for the course. The resources were scored on a six-point scale: "did not use", "very ineffective", "somewhat ineffective", "neutral", "somewhat effective", and "very effective". Table 8 shows that the other course resources, the lecture recordings and the face-to-face lectures score high for Fontys students. And though they score lower for the TU/e students, the reported order of effectiveness is equal to the one reported by Fontys students.

We used Spearman's Rank Order correlation to investigate relationships between these answers and the number of times that students reported to have used the recorded lectures. Students who rank the online virtual learning environment as more effective tend to use recorded lectures more $\left(r_{s}=0.388, n=513, p<0.0005\right)$. A weak positive relationship was found between attending fewer live lectures and the use of recorded lectures $\left(r_{s}=0.239, n=513, p<0.0005\right)$. Of the students who never used recorded lectures, $66.1 \%$ said they always or almost always attended lectures in person. For students that used recorded lectures more than 10 times, that percentage is only $40.0 \%$.

When asked the reasons for not attending face-to-face lectures, only $6.8 \%$ of the Fontys students and $14.3 \%$ of the TU/e students indicated that they prefer recordings over attending the lecture. Table 9 shows that more Fontys students $(44.7 \%, n=46)$

Table 8. Indicated effectiveness in helping to succeed in the course.

\begin{tabular}{lcc}
\hline & \multicolumn{2}{c}{ Somewhat or very effective } \\
\cline { 2 - 3 } & Fontys $(n=103)(\%)$ & TU/e $(n=414)(\%)$ \\
\hline Other course resources (slides, lecture notes, etc.) & 93.2 & 74.6 \\
Lecture recordings & 90.3 & 66.5 \\
Attending face-to-face lectures & 81.5 & 66.6 \\
Online Virtual Learning Environment & 74.8 & 49.3 \\
Other Students & 35.9 & 48.1 \\
Going to professor or teachers assistant office hours & 30.0 & 29.9 \\
\hline
\end{tabular}


Table 9. Reasons to not attend one or more live lectures.

\begin{tabular}{lcc}
\hline & Fontys $(n=46)(\%)$ & TU/e $(n=103)(\%)$ \\
\hline Attended all the lectures for this course & 44.7 & 29.3 \\
Travel distance & 11.7 & 18.4 \\
Disabilities and/or medical conditions & 13.6 & 7.5 \\
Work commitment & 5.8 & 15.9 \\
I prefer the recorded lecture over attending the & 6.8 & 14.3 \\
$\quad$ lecture & & \\
Other study-related activities & 3.0 & 15.7 \\
I prefer not to attend lectures & 1.0 & 7.5 \\
\hline
\end{tabular}

than TU/e students $(29.3 \%, n=103)$ report to have attended all the lectures for the course. Examples of other study-related activities given by students included project activities or other lectures/courses at the same time as the lecture in question.

A number of students commented that they did not think the lecturer minded that they were not present as long as there was a big enough group of students that did attend the lecture. One student of the Chemical Biology course said during the interview:

The lecturer does not mind it if students are not always present. He always has a group of about 70 students that attend the lecture. So nobody really notices it when you're not there. (IVR1)

Another student, from the Methods and models in behavioural research course, thought that some lecturers preferred smaller groups:

Some lecturers have problems with keeping order in large groups or get nervous if a lot of students talk during the lecture. Now, only the students that are motivated are there and the rest watches the recordings. (IVR5)

\section{Discussion}

Students use recorded lectures as a replacement for missed lectures, either incidentally or as a structural replacement for lectures. They also use them for specific purposes, such as exam preparation, reviewing of material before a lecture or to improve the retention of lecture materials. This conforms with the findings of Traphagan (2006), Veeramani and Bradly (2008) and Gosper et al. (2008).

A large number of students report that they view most of the recorded lectures. This is consistent with Gosper et al. (2008) who, based on a sample of 815 students, reported that $71 \%$ of the respondents stated that they listened to the entire recording. It is, however, higher than Traphagan (2006) where only $46 \%$ or respondents out of a group of 488 said they watched the complete recordings.

The results show interesting differences in use between students from Fontys and TU/e. The Fontys students use the recorded lectures more than the TU/e students for activities such as managing distractions during lectures, checking their notes, reinforcing the experiences obtained at the live lecture and reviewing material before and after a lecture. These differences can be caused by differences in previous experience (or lack thereof) with recorded lectures, differences in gender, contents of the actual recorded lectures, course or department. Additional research is needed to determine the extent of the effect of each of these possible influencers. 
Their reported interest in the topic of the course, the indicated importance of that topic for their study and the grade that students aim for does not appear to influence the number of times that students use the recorded lectures.

In the interviews, even when prompted, students never mentioned quality of the lecture or lack thereof as decisive for watching or not watching a recorded lecture. Practical considerations like already having attended the lecture live or lack of time were much more important. There is a tendency that the recorded lectures for courses that only use the blackboard are viewed less often. This confirms the findings by Traphagan (2006) that while some students are tempted to skip class because of recorded lectures, other factors affect attendance as much or more than the availability of recorded lectures does.

This research does not question the length, structure or contents of the lectures that are being recorded, even though those might merit reconsideration. Our goal was to research the use of recorded lectures in their current setting.

The collected data is based on verbal reports, in this case by students, of their use of recorded lectures. Surveys are prone to a number of errors (Deming 1944). Methodological triangulation (Denzin 2006) increases the credibility and validity of the results provided by the surveys. Research by Sheard et al. (2003) shows it is possible to infer student learning behaviour from their interaction with the system. The LCS used at Fontys and TU/e keeps a log of the students' interactions with the recorded lectures. This data can also be used to get a more detailed view of the students' navigation within the recorded lectures.

\section{Conclusions}

The goal of this study was to get a better understanding of how students use the recorded lectures available at this moment. This is a first step towards the aim to improve the support for recorded lectures within different usage scenarios. Indeed, our study shows that different usage scenarios may apply. Students use recorded lectures to serve different purposes, such as replacement for lectures, exam preparation and reviewing material. Students of Higher Vocational Education seem to use recorded lectures more often than University students to check their understanding of a lecture they visited. We could not identify a relation between usage of recorded lectures and their quality or the importance of the topics covered.

Students know where to find the recordings and technical difficulties are seldom a reason not the watch the recorded lectures. Most technical problems occur when students view the recorded lectures from home.

In the next stage of the research, we will use the LCS logs to further study the above mentioned student usage scenarios for recorded lectures in a more quantitative way. This will enable us to better guide them to those parts of the lectures that they want to view given their intended purpose of use of the recorded lecture.

\section{Acknowledgements}

This research has been funded by Fontys University of Applied Sciences. The authors would like to thank the Student Office of TU/e and the School of Nursing for their assistance in this survey. 


\section{References}

Baecker, R. M., Moore, G. \& Zijdemans, A. (2003) 'Reinventing the lecture: webcasting made interactive', in Proceedings of HCI International 200, Crete, ed. C. Stephanidis, Lawrence Erlbaum Associates, Mahwah, New Jersey, United States, pp. 896-900.

Behr, A. L. (1988) 'Exploring the lecture method: an empirical study', Studies in Higher Education, vol. 13, pp. 189-200.

Belanger, Y. (2005) Duke University iPod First Year Experience Final Evaluation Report, Center for Instructional Technology, Durham.

Campbell, G. (2005) 'There's something in the air: podcasting in education', EDUCAUSE Review, vol. 40, pp. 33-44.

Chan, A., Lee, M. \& Mcloughlin, C. (2006) 'Everyone's learning with podcasting: a Charles Sturt University experience', in Proceedings of the 23rd Annual Conference of the Australasian Society for Computers in Learning in Tertiary Education: Who's Learning? Whose Technology?, eds L. Markauskaite, P. Goodyear \& P. Reimann, Sydney University Press, Sydney, pp. 111-120.

Chang, S. (2007) 'Academic perceptions of the use of Lectopia: a University of Melbourne example', in Proceedings ascilite Singapore, eds R. J. Atkinson, C. McBeath, S. K. A. Soong \& C. Cheers, Centre for Educational Development, Nanyang Technological University, Singapore, pp. 135-144.

Day, J. (2008) Investigating Learning With Web lectures, Dissertation thesis, Georgia Institute of Technology.

Deming, W. E. (1944) 'On Errors in Surveys', American Sociological Review, vol. 9, pp. $359-369$.

Denzin, N. (2006) Sociological Methods: A Sourcebook, Transaction Publishers, Piscataway, NJ.

Fardon, M. (2003) 'Internet streaming of lectures: a matter of style', in Conference Proceedings of Educause in Australasia, University of Adelaide, Adelaide, pp. 699-708.

Gibson, J. J. (1979) The Theory of Affordances. The Ecological Approach to Visual Perception, Lawrence Erlbaum Associates, Hillsdale, NJ.

Gosper, M., et al. (2008) The Impact of Web-Based Lecture Technologies on Current and Future Practices in Learning and Teaching, Australian Learning \& Teaching Council, Strawberry Hills, NSW.

Hall, D. (2009) MyMedia Student Evaluation 2009, Centre for Learning and Professional Development, University of Adelaide, Adelaide.

Kishi, C. \& Traphagan, T. (2007) 'Lecture Webcasting at the University of Texas at Austin', in Proceedings of the 23rd Annual Conference on Distance Teaching \& Learning, University of Wisconsin, Madison, WI, pp. 1-5.

Laurillard, D. (2002) Rethinking University Teaching: A Framework for the Effective Use of Educational Technology, Routledge, London.

Leoni, K. \& Lichti, S. (2009) Lecture Capture in Higher Education, Northwestern University, Evanston, IL.

Phillips, R. (2005) 'Challenging the primacy of lectures: the dissonance between theory and practice in university teaching, Journal of University Teaching \& Learning Practice, vol. 2, p. 2.

Schok, M. (2007) Videocolleges op de TU/e [Recorded lectures at the TU/e], SURFnet Expertiseseminar: Streaming video in de onderwijspraktijk [SURFnet Expert seminar: streaming video in practice], Utrecht.

Sheard, J., et al. (2003) 'Inferring student learning behaviour from website interactions: a usage analysis', Education and Information Technologies, vol. 8, pp. 245-266.

Sheely, S. (2006) 'Persistent technologies: why can't we stop lecturing online?', in Proceedings of the 23rd Annual Conference of the Australasian Society for Computers in Learning in Tertiary Education: Who's Learning? Whose Technology?, eds L. Markauskaite, P. Goodyear \& P. Reimann, Sydney University Press, Adelaide, pp. 769-774.

Sonicfoundry. (2010) MediaSite [Online]. Available at: http://www.sonicfoundry.com/mediasite/

TNS Opinion \& Social. (2010) E-Communications Household Survey - Summary. Eurobarometer Survey. EU Directorate General Information Society and Media, Brussels.

Traphagan, T. (2005) Class Lecture Webcasting, Fall 2004 and Spring 2005: A Case Study, University of Texas, Austin, TX. 
Traphagan, T. (2006) Class Lecture Webcasting, Fall 2004, Spring 2005, and Fall 2005: Summary of Three Case Studies, University of Texas, Austin, TX.

Traphagan, T., Kucsera, J. \& Kishi, K. (2010) 'Impact of class lecture webcasting on attendance and learning', Educational Technology Research and Development, vol. 58, pp. 19-37.

Udell, J. (2004) Name that Genre: Screencast [Online]. IDG Network. Available at: http:// weblog.infoworld.com/udell/2004/11/15.html\#a1114

Veeramani, R. \& Bradly, S. (2008) Insights Regarding Undergraduate Preference for Lecture Capture, University of Wisconsin-Madison E-Business Institute, Madison, WI.

Wieling, M. (2008) De effecten van het aanbieden van videocolleges als aanvulling op de reguliere hoorcolleges binnen de Faculteit Rechten [The effects of recorded lectures as a supplement to regular lectures at the Law department]. Groningen University, Groningen.

Williams, J. \& Fardon, M. (2007) 'Perpetual connectivity: lecture recordings and portable media players', in Proceedings ascilite Singapore 2007, eds R. J. Atkinson, C. McBeath, S. K. A. Soong \& C. Cheers, Centre for Educational Development, Nanyang Technological University, Singapore, pp. 1084-1092.

Woo, K., et al. (2008) 'Web-based lecture technologies: blurring the boundaries between faceto-face and distance learning', $A L T-J$, vol. 16 , pp. 81-93.

Zupancic, B. (2006) Vorlesungsaufzeichnungen und digitale Annotationen: Einsatz und Nutzen in der Lehre [Lecture recording and digital annotations: Use and benefits in teaching], Dissertation, Universität Freiburg, Fakultät für Angewandte Wissenschaften. 